Article

\title{
Development of a Simplified Agency Life-Cycle Costing Tool for Gravel Roads
}

\author{
John Rolt, Kenneth Mukura and Andrew Otto * \\ TRL Limited, Crowthorne House, Nine Mile Ride, Wokingham RG40 3GA, UK; johnsrolt@gmail.com (J.R.); \\ kmukura@trl.co.uk (K.M.) \\ * Correspondence: aotto@trl.co.uk
}

Received: 10 April 2020; Accepted: 30 May 2020; Published: 2 June 2020

check for updates

\begin{abstract}
Understanding how roads behave is necessary both for their design and also to make sure that suitable and appropriate maintenance is programmed and carried out effectively. The problem is that this is not an easy task because there are many variables that affect road performance, and these differ from place to place. This is true of both paved and unpaved roads. Most countries have a large network of rural unpaved roads that require regular maintenance at relatively high total cost over many years. If the performance of such roads can be improved, especially in whole life terms, their costs can be reduced. Decision support tools such as the highway development and management system have been developed based on several studies in different countries. The performance models developed as a result of these studies often contain many variables and require extensive data collection before they can be used. This is often beyond the resources available. To improve this situation and to develop better understanding of the performance of gravel roads, this study was undertaken in six countries. It was found that two material characteristics, namely plasticity product and grading modulus, had a major effect on the performance of gravel roads, and were found to predict the performance of gravel roads to an acceptable level of accuracy. The results of the study were used to develop a simple life-cycle costing model for gravel roads that allows engineers to improve the performance of gravel roads and to reduce whole life costs.
\end{abstract}

Keywords: life-cycle cost; gravel roads; gravel loss; roughness

\section{Introduction}

Background

In 2016, the Research for Community Access Partnership (ReCAP), funded by UKAid, launched a project entitled 'Development of Guidelines and Specifications for Low Volume Sealed Roads through Back Analysis.' The project is being undertaken by Transport Research Laboratory (TRL) Limited. The overall objective of the project is to undertake a review of the performance of a range of low-volume sealed roads (LVSRs) constructed in the last four decades. Though the study is focused towards LVSRs, practitioners expressed the need to revisit certain aspects of gravel roads since these constitute a large proportion of their network. One of the key tasks of the project was to provide a database of existing LVSRs that have been investigated related to pavement type and materials, performance, and environmental conditions.

This approach of developing a database of road performance data from a wide range of research studies in order to improve analysis and therefore the quality of design and construction is not new. The approach was most famously used in the USA where the data from the American Association of State Highway Officials (AASHO) Road Test and later the Strategic Highways Research Program 
(SHRP) was made readily available. However, it has not been used in many other places and not within research on low volume roads (LVRs).

To date, a web-based database (www.lvroadsdata.com) containing data from a number of studies has been created and continues to be updated. The main discussion of this paper is based on data obtained from gravel road performance studies undertaken through the support of the International Labor Organization (ILO) and the UK Department for International Development (DFID) and now contained in the database.

\section{The General Problem}

Ideally, roads are designed to minimize whole life transport costs. Whole life costs (WLCs) include the costs to road users and to the economy as a whole, hence minimizing WLCs is best for the economy. However, to design roads to achieve this, it is necessary to understand exactly how roads behave. If this is not fully understood there are dangers of under-design and early deterioration, or over-design and wasteful expenditure. Unfortunately, fully understanding how roads behave is not a simple task. This is because there are many variable factors that affect road performance, and these vary in extent from region to region. These include but are not limited to:

- Properties of the available road building materials;

- Environmental factors including rainfall, temperature, and the effects of climate change;

- Design factors such as pavement layer strengths and thicknesses;

- Properties of the road foundation (subgrade);

- Design factors such as quality of drainage and associated parameters such as embankment height;

- Terrain (geomorphology);

- Traffic volume and loading;

- Quality of construction; and

- Quality of maintenance.

Most road authorities and agencies have expressed concerns over the high cost associated with sustaining rural unpaved roads in general. Whilst some roads last quite well before re-gravelling is required, others have very short re-gravelling cycles of two to three years, and sometimes up to $150 \mathrm{~mm}$ of imported gravel lasts for less than a year. Under these circumstances the cost of sustaining such networks exceeds the capacity of the responsible authorities, hence the poor state of the roads that result. With increased awareness, road users are demanding better services in line with levies and taxes that they pay for road provision; as a result, good riding quality and low vehicle operating costs are now an issue. To achieve this, most authorities have adopted performance-based maintenance techniques in which the quality of road determines the work that needs to be done to maintain the desirable standards.

Low-volume earth and gravel roads are often constructed by labor-based methods using quite different construction techniques and lighter equipment than is used on projects constructed by conventional machine-based methods. Quantitative information on the engineering performance and modes of deterioration of these types of road is limited, and thus it is difficult to set appropriate standards or to know the effect of different standards on the performance of the roads. This means that the expected level of maintenance is difficult to ascertain, and whole-life costs and benefits are almost impossible to determine.

A scientific experiment to quantify the effect of all the variable factors would be prohibitively expensive. Research studies have concentrated on those variables that are considered to be the most important but even that has often proved to be inadequate. Indeed, the most comprehensive recorded full-scale road experiment ever carried out, namely the AASHO Road Test conducted in 1958/60 in the USA that led directly to the road pavement design method used in the United States of America, Highway Research Board (HRB) [1], only dealt with one climate and one subgrade although many features of the study were unique and comprehensive. Thus, several key independent variables were 
not and could not be included. Extending the results to the range of the factors that were not catered for in the experimental design has sometimes proved difficult. Indeed, the United States Federal Highway and Administration [2] gravel road design and maintenance uses only plasticity characteristics and particle size distribution to specify material for use on gravel roads.

Research on gravel roads in Sub-Saharan Africa has often been done in isolation and hence different variables are often considered by different researchers. Notable studies are Hodges, Rolt, and Jones [3]; Paige-Green [4]; SweRoad and Department of State Roads Zimbabwe [5]; van Zyl, Henderson, Fourie [6], and Mukura [7].

For example, the three independent studies on gravel loss and roughness by Hodges et al. [3], SweRoad and the Department of State Roads Zimbabwe [5], and Mukura [7] developed models that use different variables. It should be noted, however, that the studies took place at different times between 1972 and 1999.

Rainfall, gradient of the trial sections, traffic flow, rutting, roughness, and gravel loss on over 42 sections of road were measured by Hodges et al. [3]. A model was produced for the prediction of gravel loss with the variables rainfall, gradient, traffic flow, and calibration factors for four different material types (e.g., volcanic gravels). However, the study does not show the site-specific data of annual rainfall. Instead sites are reported as either having rainfall less than $1000 \mathrm{~mm} /$ year or more than $1000 \mathrm{~mm} /$ year.

Rainfall, traffic flow, roughness, gravel loss, the particle size distribution of the gravels, the Atterberg limits of the gravels, and in some cases the aggregate impact value (AIV) of the gravels were all included in the SweRoad and Department of State Roads Zimbabwe [5] study. Twenty-one sections were studied. The material types were recorded for each section, as were the changes in materials' properties. Unfortunately, the gradients for each section were not reported. The measured values of roughness and gravel loss were compared with Highway Development and Management Model 4 (HDM4) predictions in flat terrain. Many cases of disagreement between the measured and predicted values were noted. One key variable that was measured (although not used), is the strength of the gravel particles. Logically, one would expect that weaker gravel particles would undergo some element of crushing (from heavy vehicle loads) and attrition from tire friction and should therefore expect particle strength to be included in the gravel loss models. The importance of degree of compaction to the initiation of gravel loss was also reported by Mukura [7]. Inclusion of these factors could improve the accuracy of the predictions of the models and perhaps support the case for sufficient compaction of gravel roads in order to minimize gravel loss as shown by van Zyl et al. [6].

Therefore, because different variables were used and some important ones excluded, combining data from the independent studies to enable meta-analysis was not feasible.

Although basic correlation between performance variables and independent variables such as the properties of the pavement materials, climate characteristics, and traffic is relatively easy to determine and to verify statistically, actual modelling of the performance in terms of all the variables and their complex interactions may often be almost impossible. Nevertheless, performance correlations indicate the factors on which performance depends even though the magnitude of any effect may not be easily quantifiable, and the correlations indicate how better performance can be obtained.

In this study, the approach was to focus on two key materials' characteristics that affect performance of gravel wearing course in relation to traffic. The two major materials' variables used were plasticity product and grading modulus. The study was undertaken in six countries in Sub-Saharan Africa. The range of other variables that affect performance, such as rainfall and gradient, were also recorded. The rationale behind this is that if the results of the study are used within the boundaries of these variables, then reasonable outputs and decisions can be made based on the tools developed.

\section{Objectives}

Thus, the aim of the study was to develop a simplified gravel wearing course performance prediction tool. The tool is simplified in that it requires the measurement of a few key materials' 
variables and is therefore not 'data hungry' in contrast to other models that require the input of several variables. In addition, the study presents an example of the outputs of a simplified agency life-cycle costing tool for gravel roads based on the performance tool. However, it does not claim to present a more accurate gravel roads performance model compared to those incorporating more variables, but it is much easier to use and incorporates adequate accuracy given the natural and normal variability of road performance. Use of the tool enables maintenance units to easily estimate the agency life-cycle cost of maintaining gravel roads based on the materials available in the area.

Data on the performance of gravel roads in six separate studies carried out in six countries (Ethiopia, Ghana, Lesotho, Mozambique, Uganda, and Zimbabwe) were collected and analyzed.

\section{Study Methodology}

\subsection{Introduction}

It is therefore important that factors influencing deterioration and the maintenance requirements are investigated and understood so that, through engineering knowledge, processes and standards can be put in place that minimize the problems. To achieve this objective, current standards and specifications, which are generally focused on structural strength, needed reviewing in order to develop new standards based on improving overall performance. The performance of unpaved roads depends particularly on the quality of materials used (especially for the surfacing layer), the workmanship, the appropriateness of the piece of infrastructure to its intended function, and the influencing environment. The measure of performance is paramount to the whole process and, in the case of unpaved roads, performance is measured by the rate of gravel loss, the initial roughness and rate of roughness progression, and ultimately by the life-cycle costs. Ultimately for the road agency, life-cycle cost is very important. Paige-Green and Visser [8] showed that correct prediction of deterioration can lead to savings of up to $20 \%$ in small networks. If it is scaled up, then the overall agency savings can be substantial.

Quantitative information is therefore required on the deterioration for different types of very low-volume roads so that,

- Appropriate engineering standards can be set;

- Methods to monitor compliance with standards developed, and

- Procedures determined that enable total life-cycle costs to be calculated.

The importance of well-defined standards has become particularly evident with the current emphasis on private sector involvement in low-volume road projects through the training and engagement of small-scale contractors. Construction of roads by the private sector-whether highly trafficked trunk roads or village tracks-is conducted as a business and, as with any business, reducing costs increases profits. Whilst measures which reduce costs through increased efficiency are to be encouraged, those which result in poor quality are not acceptable. Without setting appropriate standards and methods to monitor compliance with these standards, it is impossible to check on the quality of roads being constructed.

To begin with, a series of projects was initiated in partnership with the International Labor Organization/Advisory Support, Information Services and Training (ILO/ASIST). A total of 63 test sites was selected in three countries, namely Ghana (24 roads), Uganda (eight roads), and in Zimbabwe (31 roads). Individual reports were produced with recommendations and guidance based on each country only. A fourth project report (Mukura [9]), was also written, synthesizing the findings from the three countries together and providing guidelines for countries with similar terrain, climate, and materials.

Nevertheless, it was recognized that the ranges of conditions and materials were still quite small compared with the potential ranges to be found in much of Africa, hence further studies were planned in Ethiopia (33 roads), Mozambique (24 roads), and Lesotho (23 roads). 
The data were analyzed, performance zones identified, and thus a gravel wearing course performance prediction tool was developed. In this study, performance is represented by gravel loss and road roughness. The performance prediction tool was further used to develop a simplified agency life-cycle costing tool for gravel roads. The data ranges used in the development of these tools are described in this paper.

Using appropriate standards and specifications will result in more sustainable and manageable road networks and therefore several benefits for road users, road agencies, and road authorities. This will include the following key components:

- Better decisions will be made at planning and design stages which will promote improved overall road network performance.

- This will

- Enable the most appropriate road types for different environments to be selected;

- Reduce the maintenance burden;

- Enhance the durability of the roads thereby reducing the demand for gravel and reducing environmental degradation;

- Increase the opportunities for the expansion of road networks and therefore improved accessibility.

- The life-cycle costing methodology will be a useful tool adding a new dimension incorporating economic considerations as an integral part of low-volume roads provision.

\subsection{Details of the data}

The behavior or deterioration of road pavements depends on many factors but the deterioration itself is effectively split into two major components, namely:

1. A primary or relatively rapid component that needs to be corrected on a regular basis if the road is to provide an acceptable level of service. This is the component that normal maintenance is designed to correct.

2. Secondary component that comprises the changes in the road characteristics that take place more slowly, but which should eventually be corrected because they adversely affect the rate of primary deterioration.

The characteristics of the deterioration depend on many other factors including:

1. Traffic characteristics;

2. Climate;

3. Terrain and the characteristics of the geometric alignment;

4. The nature of the materials used to provide the pavement layers.

The traffic composition of the study roads by country are shown in Table 1.

Table 1. Traffic levels.

\begin{tabular}{cccccc}
\hline \multirow{2}{*}{ Country (Number of Sites) } & \multicolumn{2}{c}{ Average Daily Traffic (ADT) } & \% Light Vehicles & \% Heavy Vehicles \\
\cline { 2 - 6 } & Min & Max & Average & ADL & ADH \\
\hline Ethiopia (30) & 4 & 266 & 81 & 68 & 32 \\
\hline Ghana (24) & 3 & 462 & 127 & 62 & 38 \\
\hline Lesotho (25) & 6 & 443 & 89 & 95 & 5 \\
\hline Mozambique (29) & 20 & 252 & 125 & 88 & 12 \\
\hline Uganda (8) & 4 & 226 & 58 & 82 & 18 \\
\hline Zimbabwe (29) & 4 & 140 & 38 & 74 & 26 \\
\hline
\end{tabular}




\subsubsection{Terrain and Climate}

The terrains in which the test sites were located, together with the climatic descriptions, are shown in Table 2.

Table 2. Terrain and climate of test site locations (and numbers).

\begin{tabular}{cccc}
\hline \multirow{2}{*}{ Terrain } & \multicolumn{3}{c}{ Climate } \\
\cline { 2 - 4 } & Semi-Arid & Dry Sub-Humid & Moist Sub-Humid \\
\hline \multirow{4}{*}{ Flat } & Ethiopia (4) & Ethiopia (1) & Ethiopia (7) \\
& Ghana (10) & Ghana (2) & Ghana (1) \\
& Zimbabwe (5) & Zimbabwe 12 & Zimbabwe (2) \\
& Uganda (1) & Mozambique (12) & \\
& Mozambique (8) & Ethiopia (4) & Ethiopia (6) \\
& Ethiopia (3) & Ghana (6) \\
Rolling & Uganda (1) & Zimbabwe (7) & Uganda (2) \\
& Lesotho (5) & Zimbabwe (3) & Ethiopia (4) \\
& & Uganda (3) \\
& Ethiopia (1) & Lesotho (10) & Mozambique (7) \\
Mountainous & Lesotho (8) & Mozambique (2) & Lesotho (2) \\
& & &
\end{tabular}

\subsubsection{Rainfall}

The ranges of annual rainfall obtained from the nearest meteorological station to the study sites in each country are shown in Table 3.

Table 3. Range of annual rainfall for study sites.

\begin{tabular}{cccc}
\hline \multirow{2}{*}{ Country } & \multicolumn{3}{c}{ Rainfall (mm/year) } \\
\cline { 2 - 4 } & Min & Max & Average \\
\hline Ethiopia & 730 & 1158 & 1010 \\
\hline Ghana & 539 & 1485 & 1135 \\
\hline Lesotho & 62 & 545 & 257 \\
\hline Mozambique & 238 & 1933 & 1272 \\
\hline Uganda & 462 & 2231 & 913 \\
\hline Zimbabwe & 731 & 1415 & 1010 \\
\hline
\end{tabular}

\subsubsection{Road Alignment and Geometric Characteristics}

The ranges of the vertical alignment on the sites in each country are shown in Table 4 .

Table 4. Range of test site gradients.

\begin{tabular}{cccc}
\hline \multirow{2}{*}{ Country } & \multicolumn{3}{c}{ Gradient $(\mathbf{m} / \mathbf{k m})$} \\
\cline { 2 - 4 } & Min & Max & Average \\
\hline Ethiopia & 0.0 & 84 & 37 \\
\hline Ghana & 1.0 & 23.7 & 11.6 \\
\hline Lesotho & 0.2 & 155 & 44 \\
\hline Mozambique & 0.3 & 10.3 & 1.9 \\
\hline Uganda & 11.9 & 47.8 & 27.3 \\
\hline Zimbabwe & 0.9 & 67.1 & 17.9 \\
\hline
\end{tabular}

4.2.4. Properties of the Materials used to Provide the Gravel Surfacing Layer

The properties of the materials on each trial road were measured and summarized in Table 5. 
Table 5. Material properties of the gravel wearing courses.

\begin{tabular}{|c|c|c|c|c|c|c|c|c|c|c|c|c|c|}
\hline \multirow{2}{*}{\multicolumn{2}{|c|}{ Material Property }} & \multicolumn{2}{|c|}{ Ethiopia } & \multicolumn{2}{|c|}{ Ghana } & \multicolumn{2}{|c|}{ Lesotho } & \multicolumn{2}{|c|}{ Mozambique } & \multicolumn{2}{|c|}{ Uganda } & \multicolumn{2}{|c|}{ Zimbabwe } \\
\hline & & Range & Mean & Range & Mean & Range & Mean & Range & Mean & Range & Mean & Range & Mean \\
\hline Liquid Limit & $\mathrm{WL}$ & $0-81$ & 32 & $21-48$ & 32.0 & 0 & 52 & $0-411$ & 19 & $29-55$ & 45.1 & $19-47$ & 30.0 \\
\hline Plastic Limit & PL & $0-56$ & 21 & $12-26$ & 17.9 & 0 & 31 & $0-27$ & 13 & $0-30$ & 18.8 & $13-30$ & 18.2 \\
\hline Plasticity Index & Ip & $0-36$ & 10 & $4-22$ & 13.9 & 0 & 22 & $0-14$ & 6.0 & $17-44$ & 26.4 & $0-27$ & 8.0 \\
\hline $\begin{array}{l}\text { Plasticity } \\
\text { Modulus }\end{array}$ & $\mathrm{PM}$ & $0-316$ & 98 & 136-1001 & 498 & 127 & 807 & $0-766$ & 257 & $352-1430$ & 786 & $0-1242$ & 364 \\
\hline $\begin{array}{c}\text { Plasticity } \\
\text { Product }\end{array}$ & PP & $0-101$ & 19.5 & $77-740$ & 310 & 57 & 443 & $0-470$ & 145 & $44-1030$ & 551 & $0-756$ & 211 \\
\hline Plasticity Factor & $\mathrm{PF}$ & $0-166$ & 38 & $197-751$ & 386 & 89 & 714 & $0-927$ & 304 & $0-1075$ & 479 & 0-1030 & 311 \\
\hline Dust Ratio & $\mathrm{DR}$ & $0-0.6$ & 0.2 & $0.31-0.90$ & 0.59 & 0.31 & 1.0 & $0.1-0.77$ & 0.4 & $0.13-0.87$ & 0.63 & $0.22-0.69$ & 0.50 \\
\hline $\begin{array}{l}\text { Coarseness } \\
\text { Index }\end{array}$ & Ic & $38-100$ & 70 & $12-71$ & 48 & 14 & 75 & $0-63$ & 22.5 & $33-75$ & 51 & $1-59$ & 32 \\
\hline $\begin{array}{l}\text { Grading } \\
\text { Modulus }\end{array}$ & GM & $1.8-3.0$ & 2.5 & $1.2-2.3$ & 1.9 & 1.5 & 2.6 & $0.1-2.2$ & 1.5 & $1.4-2.4$ & 2.0 & $0.9-2.14$ & 1.69 \\
\hline $\begin{array}{c}\text { Grading } \\
\text { Coefficient }\end{array}$ & Gc & 0-19 & 7.1 & $6.0-20.6$ & 15.5 & 4.9 & 17.6 & 0-19 & 7.1 & $3.1-20.5$ & 14.5 & $0.4-18.5$ & 11.3 \\
\hline
\end{tabular}

Notes: Coarseness Index (Ic) = $100-(\%$ passing 2.36$)$; Dust Ratio (DR) $=(\%$ passing 0.075$) /(\%$ passing 0.425$)$; Grading Modulus $(\mathrm{GM})=(300-(\%$ passing $2.36+\%$ passing $0.425+\%$ passing 0.075$)) / 100$; Grading Coefficient $\left(\mathrm{G}_{\mathrm{C}}\right)=(\%$ passing $26.5-\%$ passing 2.00$) \times(\%$ passing 4.75$) / 100 ;$ Plasticity Modulus $(\mathrm{PM})=(\%$ passing 0.425$) \times$ Plasticity Index; Plasticity Product $(\mathrm{PP})=(\%$ passing 0.075$) \times$ Plasticity Index; Plasticity Factor $(\mathrm{PF})=(\%$ passing 0.075$) \times$ Plastic Limit 


\subsection{Monitoring}

The test sites were regularly monitored at least twice a year for a period of approximately two years. The following surveys were conducted during each monitoring site visit:

(1) Visual condition assessment.

(2) Gravel loss measurements.

(3) Roughness measurements.

The visual condition assessment was undertaken to identify factors such as damage to shoulders and damage to side drains. These were not used directly in the development of the tool but were used to provide extra information during analysis to identify any outliers.

However, the purpose of this analysis is to identify the main factors on which the primary deterioration depends so that the design and maintenance of gravel roads can be improved in terms of riding quality (serviceability level or primarily roughness for LVRs) and at lower whole life costs, which are strongly dependent on the rates of gravel loss. Hence gravel loss and roughness progression are the two most important variables. It should be noted that other variables (not easy to quantify) such as grader operator skills also affect roughness.

The cost of gravel loss through regravelling is incurred by the road agencies, whereas the cost of gravel road roughness is incurred by the road user as increased vehicle operating costs. The dust nuisance is incurred by road users and the surrounding communities. It is therefore imperative that better prediction models for these are developed to improve the management of the unpaved road network including planning, design, and allocation of resources.

\subsubsection{Gravel Loss}

Gravel loss was estimated by monitoring cross-section profiles of the road between pairs of pegs every 20 meters along the test site as described in SweRoad, Department of State Roads Zimbabwe [5], and Mukura [7]. Gravel loss is mainly a function of the environmental factors, the traffic component, and the characteristics of the gravels used. The impact of these factors on the gravel loss values will be different in each country. Another more difficult factor to estimate is the level of compaction of the wearing course since this varies significantly over the life of the wearing course. Moreover, for gravels, the level of compaction varies from 'none' to 'good' from road to road during construction.

\subsubsection{Roughness}

Roughness measurements were carried out using a Machine for Evaluating Roughness using Low-cost Instrumentation (MERLIN) machine. Being a relatively simple tool, the MERLIN does not pick up the roughness effects of some corrugations, depending on the wave-length of the corrugations, as well as random large stones, which have a significant impact (if not dominant effect after corrugations) on riding quality. More details are provided in Cundill [10]. In some cases, the wheel tracks moved across the carriageway because drivers opted for a smoother path along the road. This simply increased the variability (or noise) in the measured values. To minimize this effect, extreme values, identified as the $5 \%$ values at both the high and low ends of the distribution of values, were ignored in the main analysis described below. The measure of spread of $90 \%$ of the MERLIN readings is referred to as ' $\mathrm{D}$.' The roughness, in terms of International Roughness Index (IRI) units, was then evaluated using the relationship in Cundill [10]:

$$
\mathrm{IRI}=0.593+(0.0471 \times \mathrm{D}) .
$$

\section{Performance}

Detailed descriptions and analyses of the performances of the individual sites were documented in the associated country reports. This section summarizes the results. These assessments indicated that traffic, material properties, primarily grading and plasticity, were the important factors in the 
performance of the sites, with the rates of gravel loss generally lower on sites that had a gravel wearing course that was fine graded and with high plasticity.

\subsection{Gravel Loss}

Typical rates of gravel loss for all the sites are listed in Table 6 .

Table 6. Observed rates of gravel loss (mm/year).

\begin{tabular}{cc}
\hline Range & Average \\
\hline $3-118$ & 27 \\
\hline
\end{tabular}

An examination of the gravel loss rates was conducted to determine the influence of variables such as traffic and material properties. The sites were divided into three groups; those with good performance (gravel loss less than $25 \mathrm{~mm} /$ year/100 vpd), marginal performance (gravel loss 20-50 mm/year/100 vpd), and poor performance (gravel loss greater than $50 \mathrm{~mm} / \mathrm{year} / 100 \mathrm{vpd}$ ). For example, the rates of gravel loss for the two groups of sites in Ghana and Uganda have been plotted against their Average Daily Traffic (ADT) levels in Figure 1.

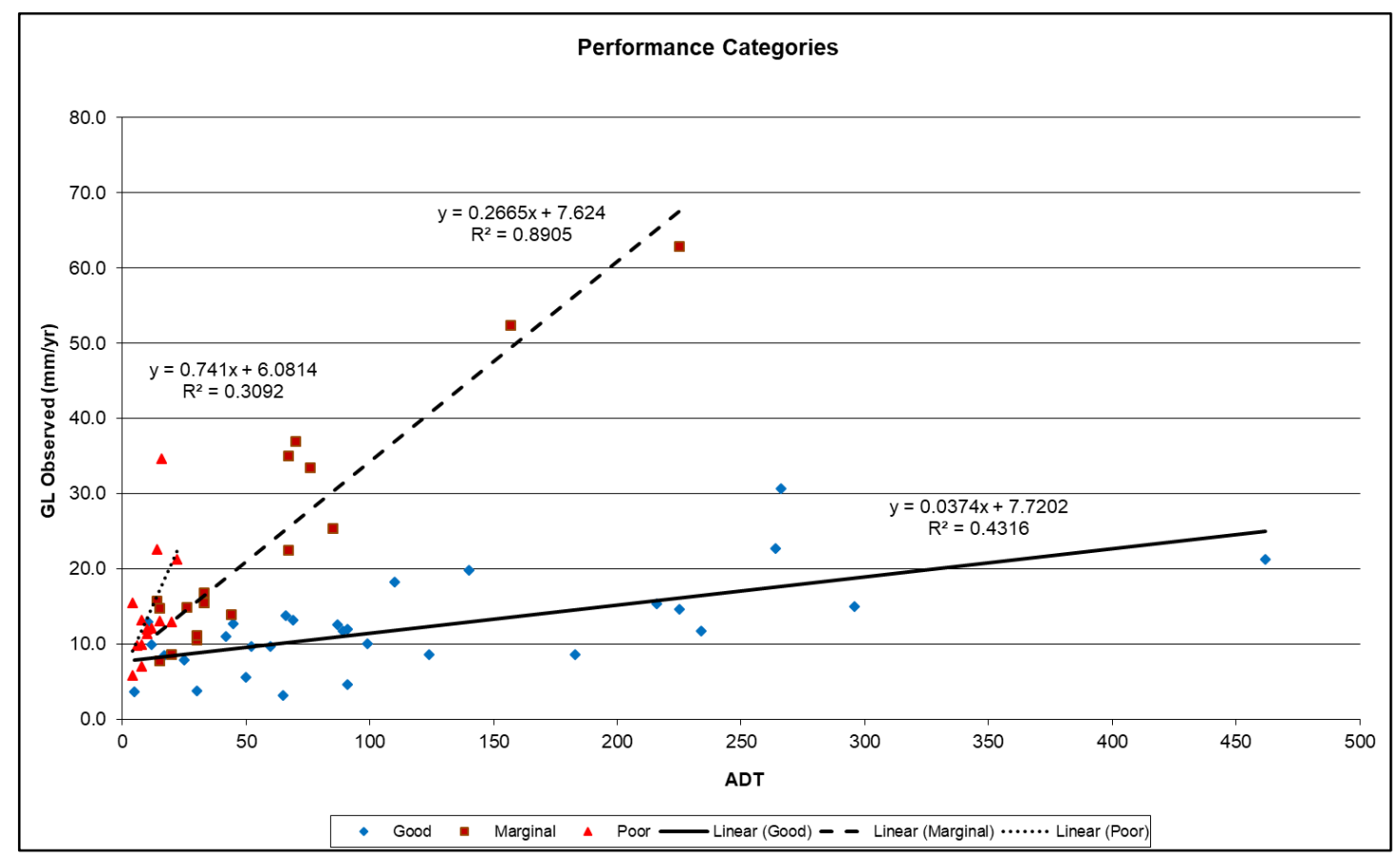

Figure 1. Rates of gravel loss in Ghana and Uganda.

The graphs in Figure 1 show that gravel loss increases linearly with ADT. In order to assess the influence of the material properties in detail, traffic was standardized to 100 vehicles/day and the observed gravel loss adjusted to correspond to an equivalent gravel loss at an ADT of 100 (GL $\mathrm{GL}_{100}$ ).

The figures also illustrate that gravel loss occurs through environmental factors such as wind and rainfall even when the traffic is zero. In order to investigate the influence of the main factors of traffic and material characteristics on the performance of the roads, the gravel loss caused by rainfall and wind (that is an environmental factor, $\mathrm{GL}_{\mathrm{E}}$, without traffic) was taken into account first.

The graph in Figure 1 illustrates that the trendlines converge to a gravel loss of approximately $7 \mathrm{~mm}$, indicating that the environmental contribution to gravel loss is significant at about $7 \mathrm{~mm} /$ year and is consistent for the three performance categories, but may vary between countries due to differences 
in rainfall. The minimum observed gravel loss in each country was used as an estimate of $\mathrm{GL}_{\mathrm{E}}$ for that country. The rate of gravel loss at 100 vehicles/day for each site was then derived using the formula:

$$
\mathrm{GL}_{100}=\left(\mathrm{GL}-\mathrm{GL}_{\mathrm{E}}\right) *(100 / \mathrm{ADT})+\mathrm{GL}_{\mathrm{E}}
$$

The rates of gravel loss estimated from the trends shown in the gravel loss/ADT data graphs have been summarized in Table 7 . These values illustrate the high rates of gravel loss observed on the sites with low plasticity gravels compared with those with high plasticity gravels (e.g., sites in both Ghana and Uganda). For example, the rates of gravel loss on the sites with high plasticity gravel (i.e., where the gravel loss is expected to be on the low side) in these two countries are similar to the average rates observed for all the sites in Zimbabwe.

Table 7. Gravel loss trends.

\begin{tabular}{|c|c|c|c|c|c|c|}
\hline \multirow{3}{*}{ ADT } & \multicolumn{6}{|c|}{ Gravel Loss (mm/year) } \\
\hline & \multicolumn{2}{|c|}{ Ethiopia } & \multicolumn{2}{|c|}{ Ghana } & \multicolumn{2}{|c|}{ Lesotho } \\
\hline & $P P>300^{(1)}$ & $P P<300$ & $\mathrm{PP}>300$ & $P P<300$ & $\mathrm{PP}>300$ & $P P<300$ \\
\hline 20 & See Note & 23 & 10 & 23 & 11 & $14-23$ \\
\hline 50 & & 34 & 11 & 25 & 12 & $16-25$ \\
\hline 100 & & 54 & 12 & 33 & 13 & $18-30$ \\
\hline 150 & & 74 & 13 & 40 & 14 & $21-36$ \\
\hline 200 & & 94 & 14 & 50 & 15 & $24-41$ \\
\hline \multirow[t]{3}{*}{250} & & 114 & 15 & 60 & 16 & $27-46$ \\
\hline & \multicolumn{2}{|c|}{ Mozambique } & \multicolumn{2}{|c|}{ Uganda } & \multicolumn{2}{|c|}{ Zimbabwe } \\
\hline & $P P>300$ & $P P<300$ & $P P>300$ & $\mathrm{PP}<300$ & $\mathrm{PP}>300^{1}$ & $P P<300$ \\
\hline 20 & 10 & 21 & 10 & 17 & See Note & 9 \\
\hline 50 & 11 & 26 & 11 & 21 & - & 12 \\
\hline 100 & 12 & 35 & 12 & 27 & - & 13 \\
\hline 150 & 13 & 43 & 13 & 34 & - & 15 \\
\hline 200 & 14 & 52 & 14 & 41 & - & 17 \\
\hline 250 & 15 & 61 & 16 & 47 & - & 19 \\
\hline
\end{tabular}

Using the values in Table 7 for gravel roads which initially have a $100 \mathrm{~mm}$ thick wearing course, regravelling will be required every three years for the low plasticity sites carrying approximately 100 vehicles per day, whereas regravelling will be required only every seven or eight years on the high plasticity sites (and in Zimbabwe) with similar traffic levels.

$\mathrm{GL}_{100}$ was derived for all the sites and the values of $\mathrm{GL}_{100}$ were used to rank the performance of the sites as 'good,' 'moderate,' or 'poor' according to their 'standardized' rates of gravel loss $\left(\mathrm{GL}_{100}\right)$ using the thresholds given in Table 8 . The quality of the gravel wearing course can be assigned to one of 'material quality zones' as illustrated in Figure 2. The charts take a similar shape (dividing into rectangular zones) to that developed by Paige-Green [4]; that is two major materials' parameters constituting the two axes and performance zones demarcated within the chart. Whereas the Paige-Green [4] charts are based on grading coefficient, the charts presented in this paper are based on grading modulus (see definitions in notes of Table 5). The reason for this is that two different materials, one fine-graded and the other coarse-graded, can possess exactly the same grading coefficient values. The materials would perform differently but the identical grading coefficient values would erroneously imply that they are the same and would perform the same way. Grading modulus does not suffer this limitation. 
Table 8. Gravel loss performance criteria.

\begin{tabular}{ccc}
\hline Performance & Zone in Figure 2 & GL $_{100}$ (mm/year/100vpd) \\
\hline Good & A & $\leq 25$ \\
\hline Moderate & B and C & $25-50$ \\
\hline Poor & D & $>50$ \\
\hline
\end{tabular}

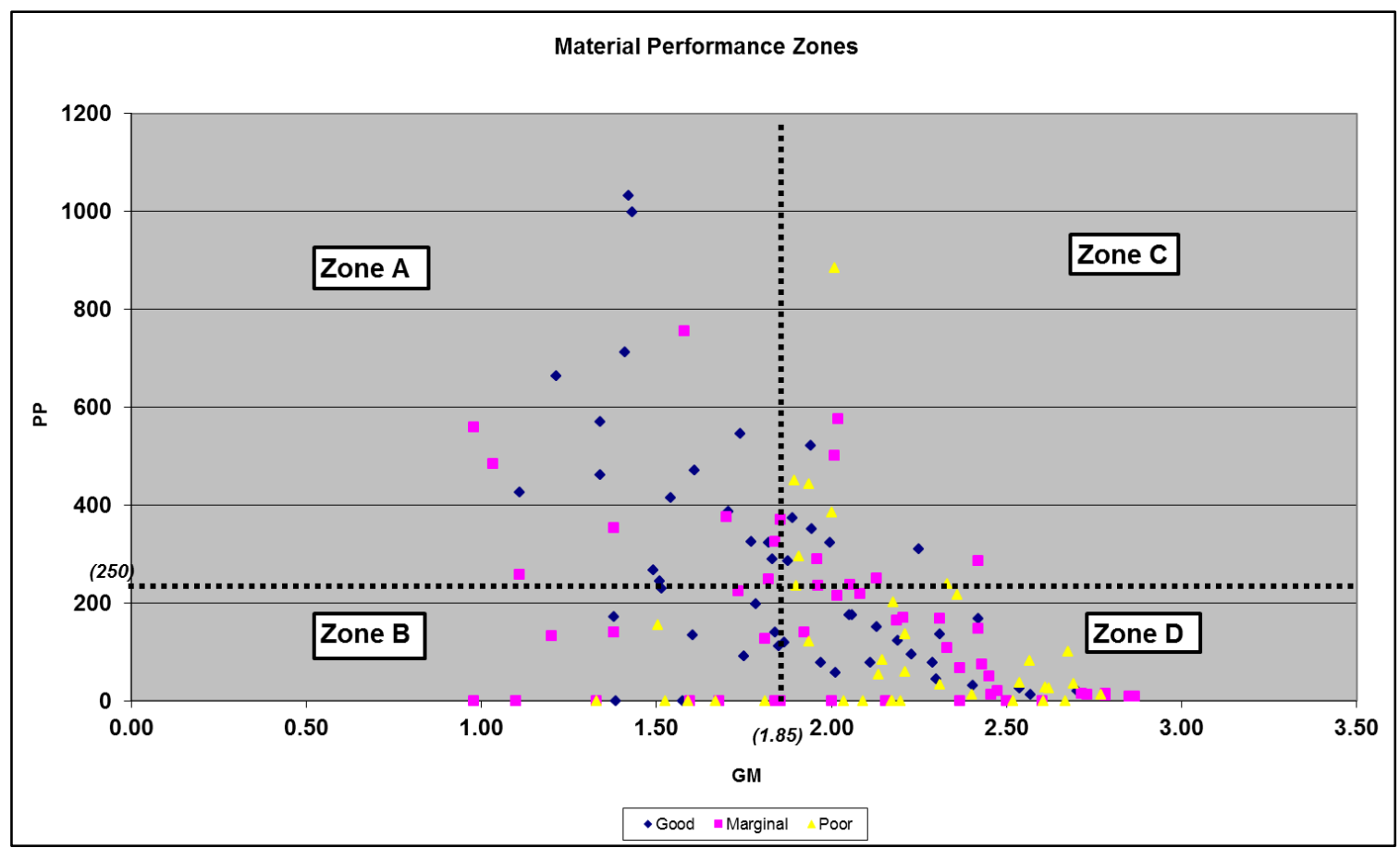

Figure 2. Gravel loss performance categories vs. material quality zones.

The higher quality materials (fine material with high plasticity) are represented by Zone A where $\mathrm{PP}>280$ and GM < 1.9. Sites with this high material quality would be expected to perform well. The lower quality material is represented by Zone D where PP $<280$ and GM $>1.9$. Sites with such low-quality material would be expected to perform poorly, with Zones B and C representing material of marginal or intermediate quality.

Materials in Zone A will almost certainly perform well since the zone does not contain any poor-performing section. However, Zone A is somewhat conservative since materials of good quality that were poorly compacted contributed to those classified in Zone D (poor-performance manifested by high gravel loss).

A later classification of appropriate materials, by Austroads [11], for use on gravel roads largely corroborates the grading modulus (GM) ranges proposed in this paper with most materials of GM 0.8 to 1.5 being suitable for use on gravel roads designed to carry up to 0.75 million equivalent standard axles (MESA).

For the next stage of the analysis, the representative rate of gravel loss for each material quality zone was determined. The 'standardized' rates of gravel loss (i.e., $\mathrm{GL}_{100}$ ) of all the sites in each Zone were plotted in a cumulative frequency graph as shown in Figure 3. 


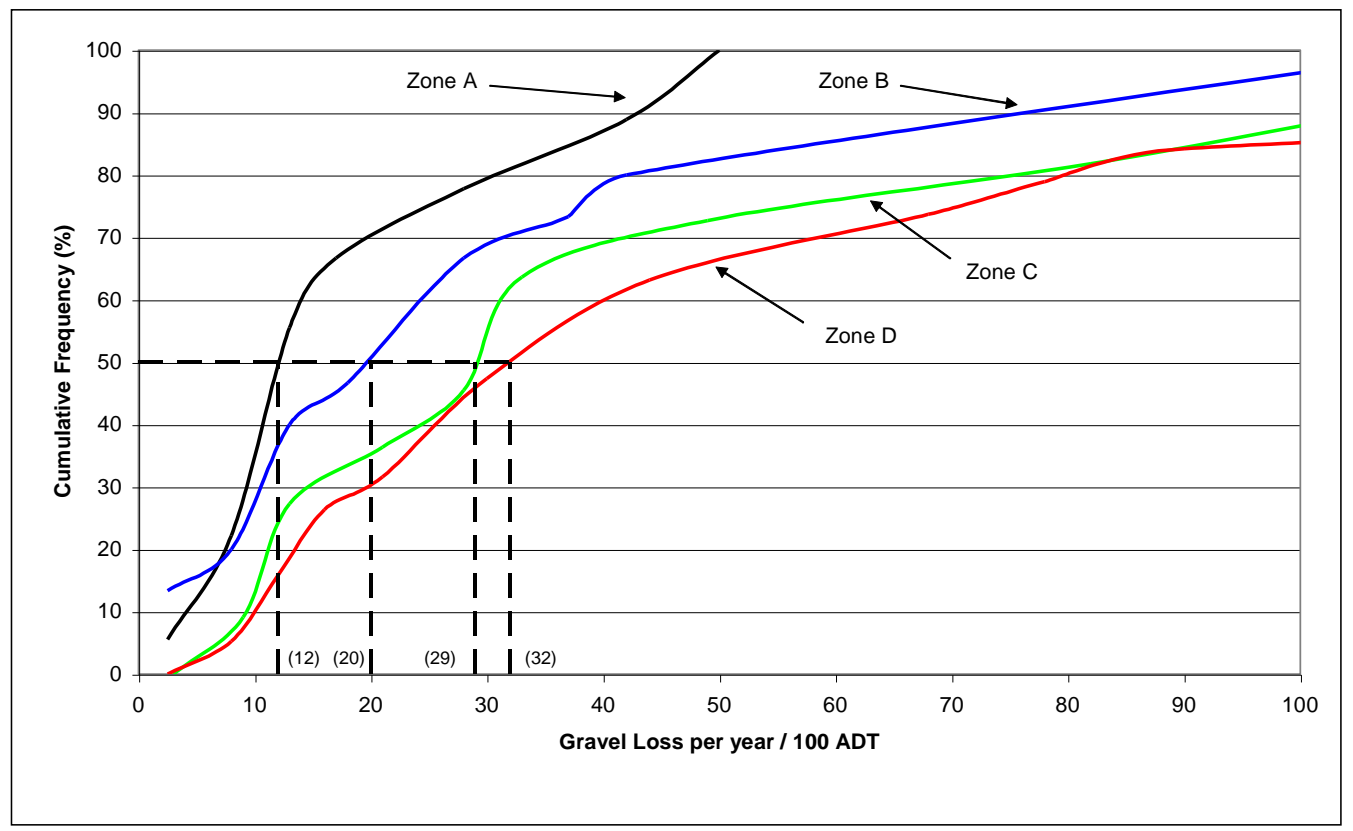

Figure 3. Cumulative frequency of standardized rates of gravel loss.

The 50th percentile values were taken as the representative rates of $\mathrm{GL}_{100}$ for each Zone. These values are listed in Table 9.

Table 9. Representative rates of gravel loss.

\begin{tabular}{cc}
\hline Material Quality Zone & Representative Rate of Gravel Loss GL $_{\mathbf{1 0 0}}$ (mm/year/100 vpd) \\
\hline A & 12 \\
\hline B & 20 \\
\hline C & 29 \\
\hline D & 32 \\
\hline
\end{tabular}

These values indicate that sites with a gravel wearing course with material properties in Zone A are likely to lose $12 \mathrm{~mm} /$ year when the ADT is 100, whereas for Zone D material, the rate of gravel loss is a factor of three times higher for similar traffic levels.

The reason behind this could be that bonding is much more enhanced in fine materials through increased surface contact in situations where plastic materials exist in the matrix and by surface tension/soil suction effects. The coarser materials, however, tend to have much smaller contact areas and, where the coarse aggregate is surrounded by fine material, the larger particles can be dislodged as a result of wheel impact. This is usually evident because these larger particles accumulate on the road shoulders as windrows.

The results also indicate that the particle size distribution of the material has a stronger influence on gravel loss than the plasticity of the material. The rates of gravel loss for sites with wearing course material that were coarse (i.e., Zones $C$ and D) were, on average, much higher than for sites with fine material (Zones A and B), with plasticity having a less significant effect.

\subsection{Roughness}

The range of roughness values and rates of increase are shown in Table 10.

Roughness on unsealed roads can be variable over short periods of time depending on variability in traffic and climate. Decreases in roughness are caused by routine maintenance activities such as spot regravelling or grading. Also, vehicles tend to travel on the least rough areas of the carriageway. 
Therefore, when roughness is measured in the wheel paths, as in this project, then decreases in roughness may be recorded simply because vehicles travel in different wheel paths or as a result of maintenance grading.

Table 10. Range of roughness values.

\begin{tabular}{cccccc}
\hline \multicolumn{2}{c}{ Roughness Values (IRI) } & \multicolumn{3}{c}{ Roughness } & Progression \\
\hline Min & Max & Average & Min & Max & Average \\
\hline 3.7 & 14.5 & 8.4 & 0.2 & 4.3 & 1.3 \\
\hline
\end{tabular}

For these reasons, positive rates of roughness progression were not recorded on a few sites. For the other sites, the observed rates of roughness progressions have been listed in Table 10.

The rates of roughness progression were standardized to a traffic level of 100 vehicles/day. However, because of the short-term fluctuations in roughness on unsealed roads, no environmental component could be determined. Thus, the rate of roughness progression per 100 vehicles/day (IRI/year/100 vpd - IRI100) was determined as a simple ratio of the observed rate of progression (IRI/year - IRIobs) as follows:

$$
\text { IRI100 }=\text { IRIobs (100/ADT) }
$$

The performances of the sites were then ranked as 'good,' 'moderate,' or 'poor' according to their 'standardized' rates of roughness progression (IRI ${ }_{100}$ ) using the thresholds given in Table 11. The observed rates of roughness progression on the sites have been plotted in Figure 4, with each site identified by its roughness performance category and with separate trendlines fitted for each category.

Table 11. Roughness performance criteria.

\begin{tabular}{cc}
\hline Performance & IRI $_{\mathbf{1 0 0}}$ (IRI/year/100 vpd) \\
\hline Good & $\leq 3$ \\
\hline Moderate/marginal & $3-6$ \\
\hline Poor & $>6$ \\
\hline
\end{tabular}

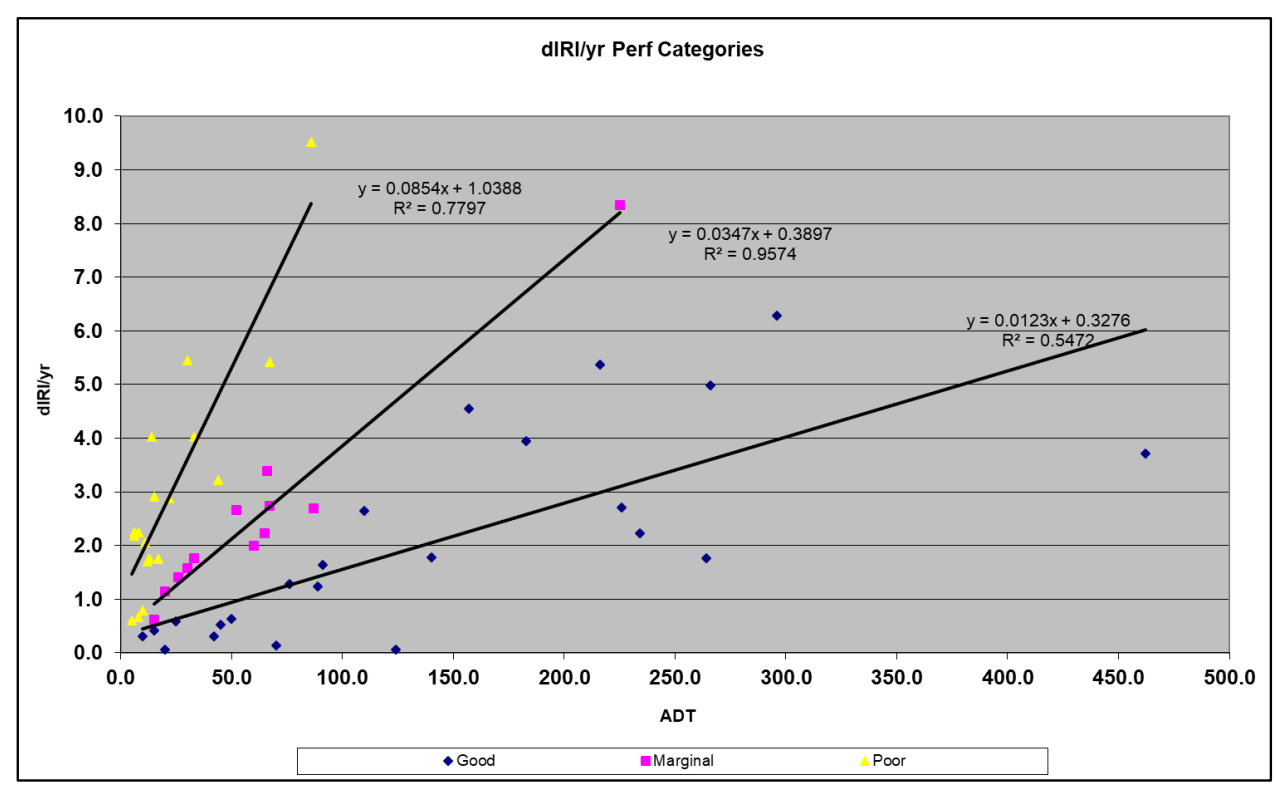

Figure 4. Observed changes in roughness by performance category. 
The trendlines for the three roughness performance categories converge to a roughness of $<1 \mathrm{IRI} /$ year. This level of roughness progression can be regarded as relatively insignificant for unsealed roads, hence the environmental contribution to roughness progression was assumed to be negligible.

Using the same four material quality zones as for gravel loss, the sites have been identified by their roughness performance category as illustrated Table 11 and Figure 5. As for gravel loss, Zone A had proportionally more of the better performing sites, whereas Zone D contained the majority of the poorly performing sites.

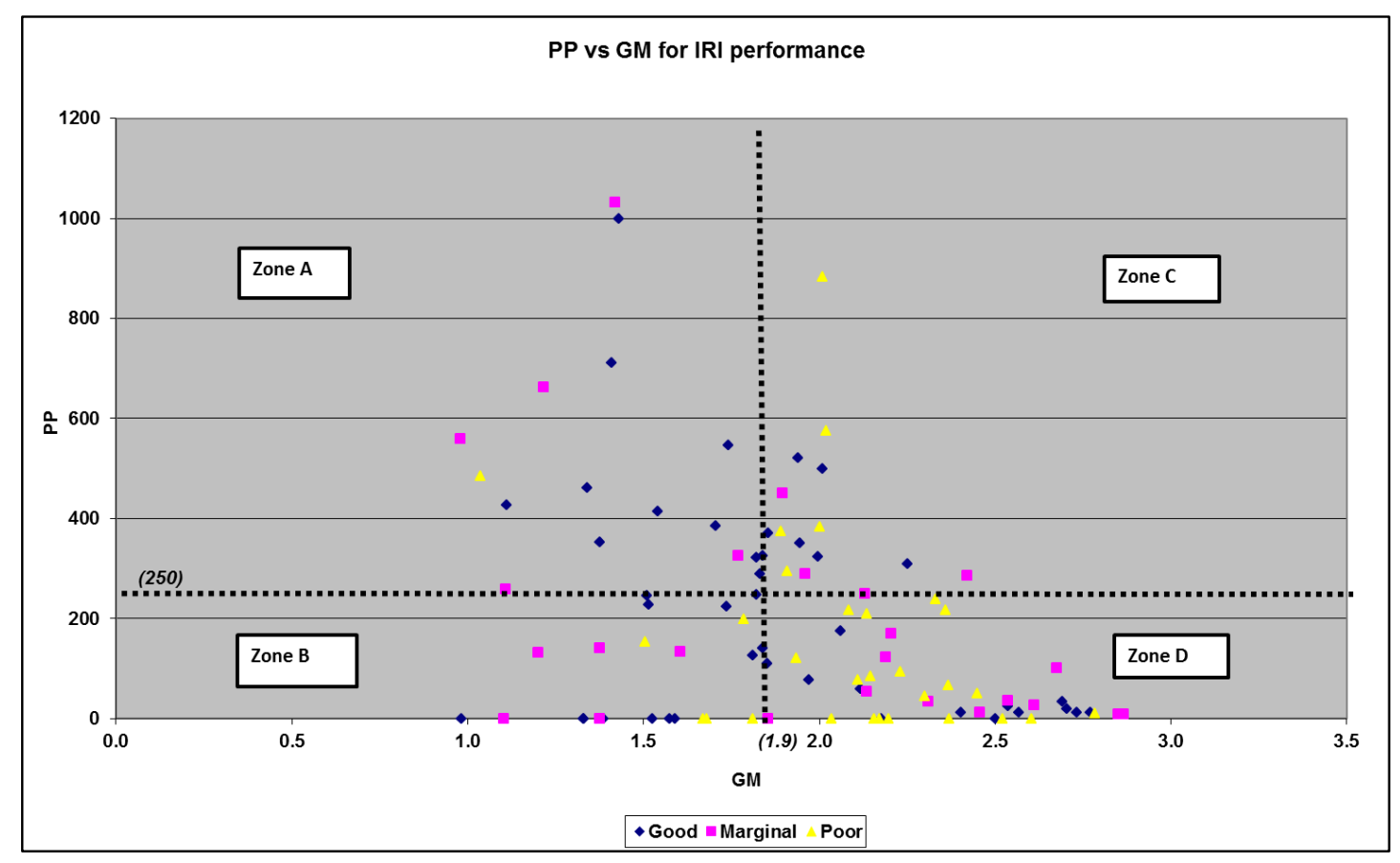

Figure 5. Roughness performance categories vs. material quality zones.

The representative rate of roughness progression for each material quality zone was determined by plotting the 'standardized' rates of roughness progression (i.e., $\mathrm{IRI}_{100}$ ) of all the sites within each Zone in a cumulative frequency graph as shown in Figure 6.

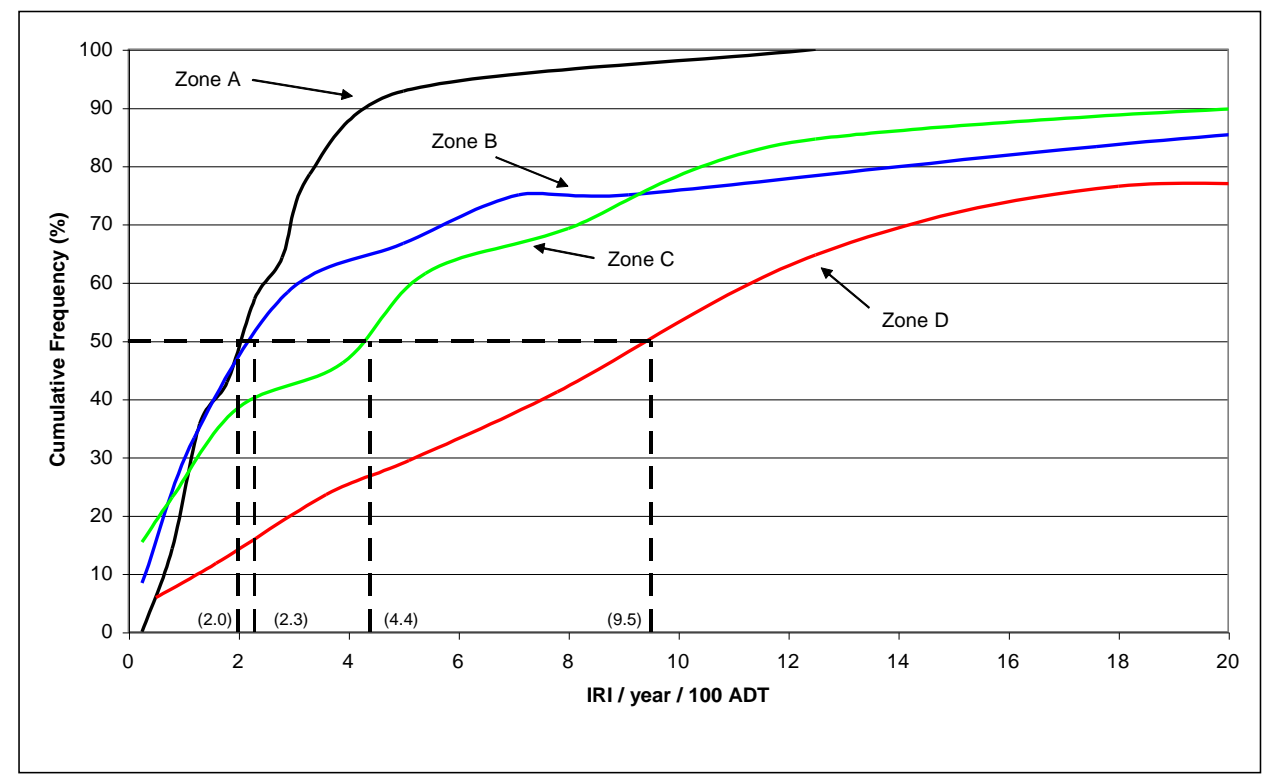

Figure 6. Cumulative frequency of standardized rates of roughness progression. 
The 50th percentile values were taken as the representative rates of IRI $_{100}$ for each Zone. These values are listed in Table 12. The percentile values give a clear representation of the rate of roughness progression and its variability.

Table 12. Representative rates of roughness progression.

\begin{tabular}{cc}
\hline Material Quality Zone & Representative Rate of Roughness Progression IRI (100 $_{\text {(IRI/year/100 vpd) }}$ \\
\hline A & 2.0 \\
\hline B & 2.3 \\
\hline C & 4.4 \\
\hline D & 9.5 \\
\hline
\end{tabular}

\subsection{Summary of Performance}

The performance in terms of gravel loss and roughness progression show the following:

1. Zone A and Zone D materials have a very large difference in performance; ( $300 \%$ difference) in performance for both gravel loss (Figure 2) and roughness progression (Figure 5).

2. Zone A and Zone B materials are also significantly different; approximately $200 \%$ difference in performance.

3. Zones $\mathrm{B}$ and Zone $\mathrm{C}$ materials are both of marginal performance in terms of gravel loss.

4. Zone $\mathrm{C}$ and Zone $\mathrm{D}$ materials are both poor in terms of roughness progression.

This is important when it comes to materials selection and general design of unpaved roads and gives rise to significant differences in life-cycle costs.

\section{Life-Cycle Cost Methodology}

The performances of the sites were assessed in terms of rates of gravel loss and roughness progression, and representative rates for each Zone were derived (see Table 9 for gravel loss and Table 12 for roughness progression).

The rates of gravel loss given in Table 9 are representative of the rates in each Zone for a traffic level of 100 vehicles/day. These rates can be transformed into rates for different levels of traffic using Equation (2) shown in Section 5.1. From these rates, the frequency of regravelling for material in each of the four Zones can be estimated for a range of traffic levels. Note that from Figure 1 rainfall accounted for only about $7 \mathrm{~mm}$ of gravel loss and change in roughness of $0.5 \mathrm{~m} / \mathrm{km}$ (Figure 4). An example of regravelling to a thickness of $150 \mathrm{~mm}$ when the gravel thickness has been reduced to $25 \mathrm{~mm}$ has been plotted in Figure 1 for traffic levels up to 500 vehicles/day.

This figure shows that for a traffic level of 10 vehicles/day, the regravelling frequency ranges from approximately every 17 years for material in Zone A to every 13 years for material in Zone D. For higher traffic levels of 100 vehicles/day, the regravelling frequency increases to every 10 years for Zone A and to every four years for Zone D.

Using graphs such as those illustrated in Figure 7, the number of times a road will need to be regravelled over its life can be estimated, knowing the quality of the gravel wearing course and the traffic volume. The cost of regravelling over the life of the road can then be estimated.

In addition to regravelling costs, life-cycle costs also include initial construction or rehabilitation costs, grading, and other routine maintenance costs such as spot regravelling and vegetation control. The frequency of some of these routine maintenance activities will depend on perceived acceptable conditions of roads for various levels of traffic. Average figures for routine maintenance can be obtained from historical data or bill of quantities (BoQs), or unit rates used by organizations.

The rates of roughness progression given in Table 12 are representative of the rates in each Zone for a traffic level of 100 vehicles/day. These rates can be transformed into rates for different levels of traffic using Equation (3) shown in Section 5.2. 


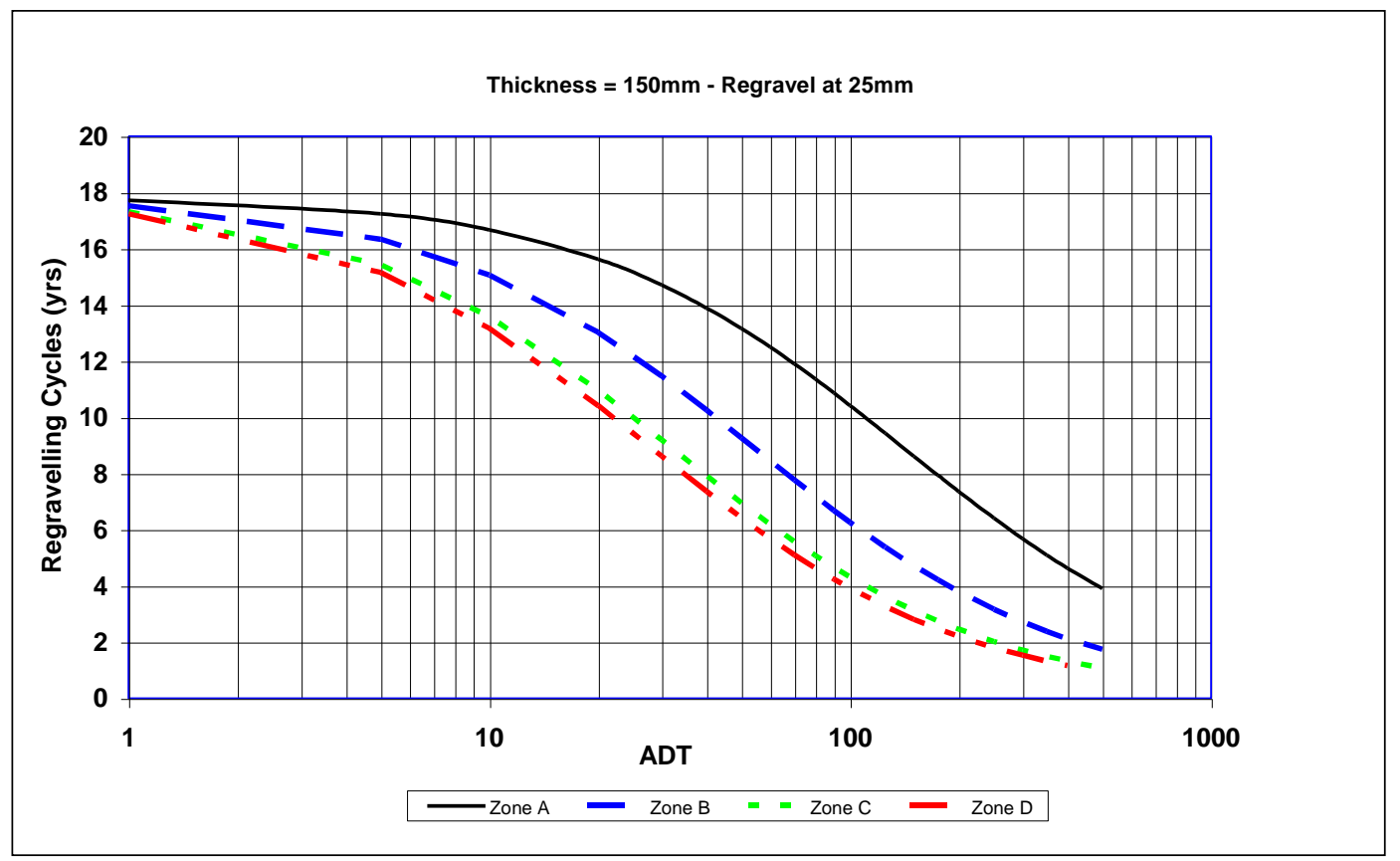

Figure 7. Regravelling frequency example.

An example of the number of gradings required over a 20-year period using an intervention level of 6 IRI to trigger grading has been plotted in Figure 8 for traffic levels up to 500 vehicles/day.

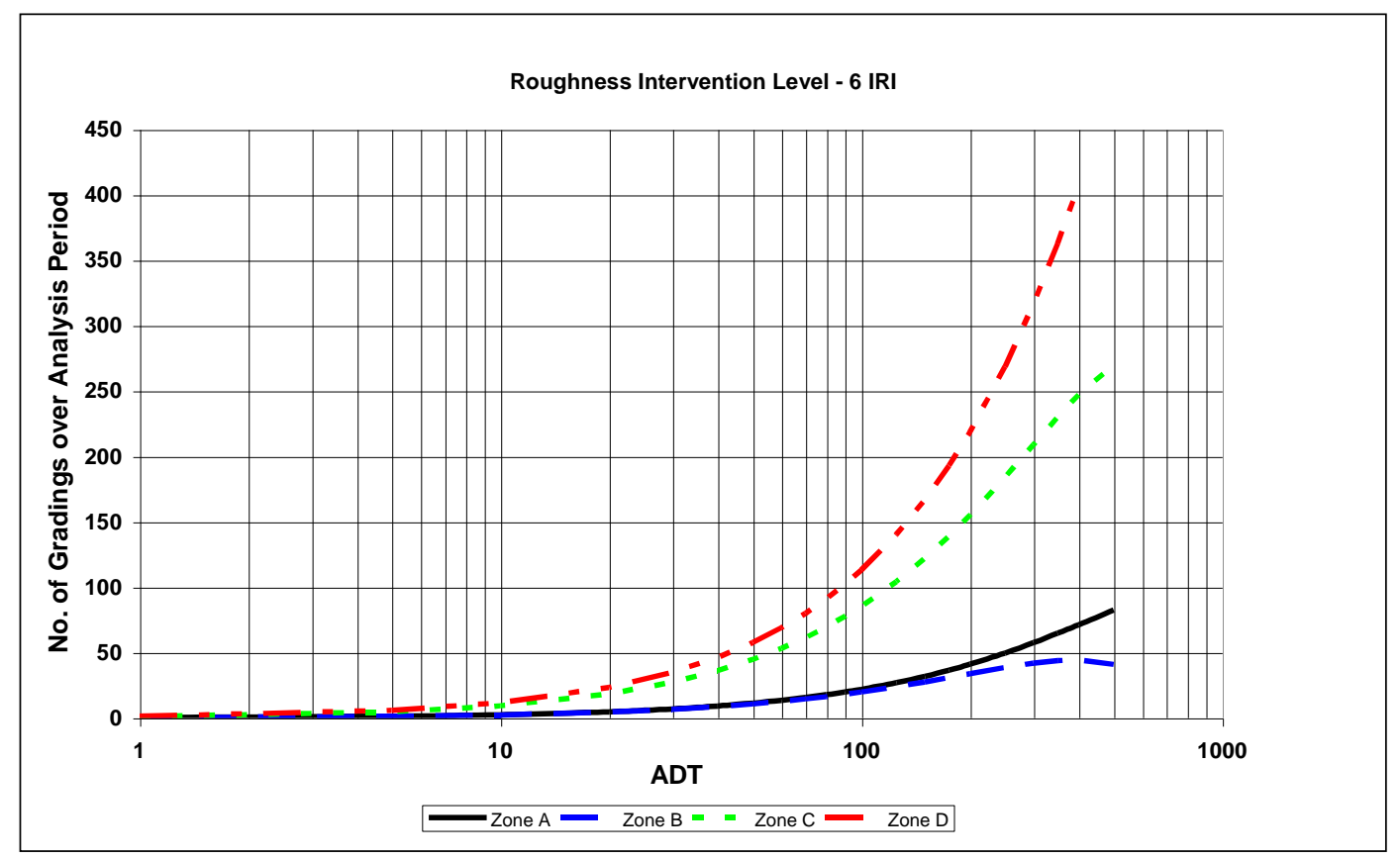

Figure 8. An illustration of required grading frequency of various material zones to maintain roughness below IRI 6.

This figure shows that if a grading is triggered whenever the roughness reaches 6 IRI, for a traffic level of 100 vehicles/day, the number of gradings over 20 years will be approximately 20 (i.e., once a year) for material in Zone A, increasing to approximately 120 gradings for material in Zone D (i.e., six gradings per year). This is based on principles of performance-based maintenance where desirable or acceptable standards are set beyond which remedial measures should be taken. Performance-based 
maintenance is becoming more widely used especially through engaging the private sector to undertake maintenance on behalf of the roads agencies. The difference in number of gradings for Zone A and Zone D clearly shows how the choice of materials during construction, rehabilitation, or regravelling will impact on the future maintenance of the road.

From graphs such as illustrated in Figure 8, the number of times a road will need to be graded over its life can be estimated, knowing the quality of the gravel wearing course and the traffic volume. The cost of grading over the life of the road can then be estimated.

A spreadsheet-based program has been developed for computing road agency life-cycle costs for various levels of traffic and for the different material quality zones as illustrated in Figure 9.

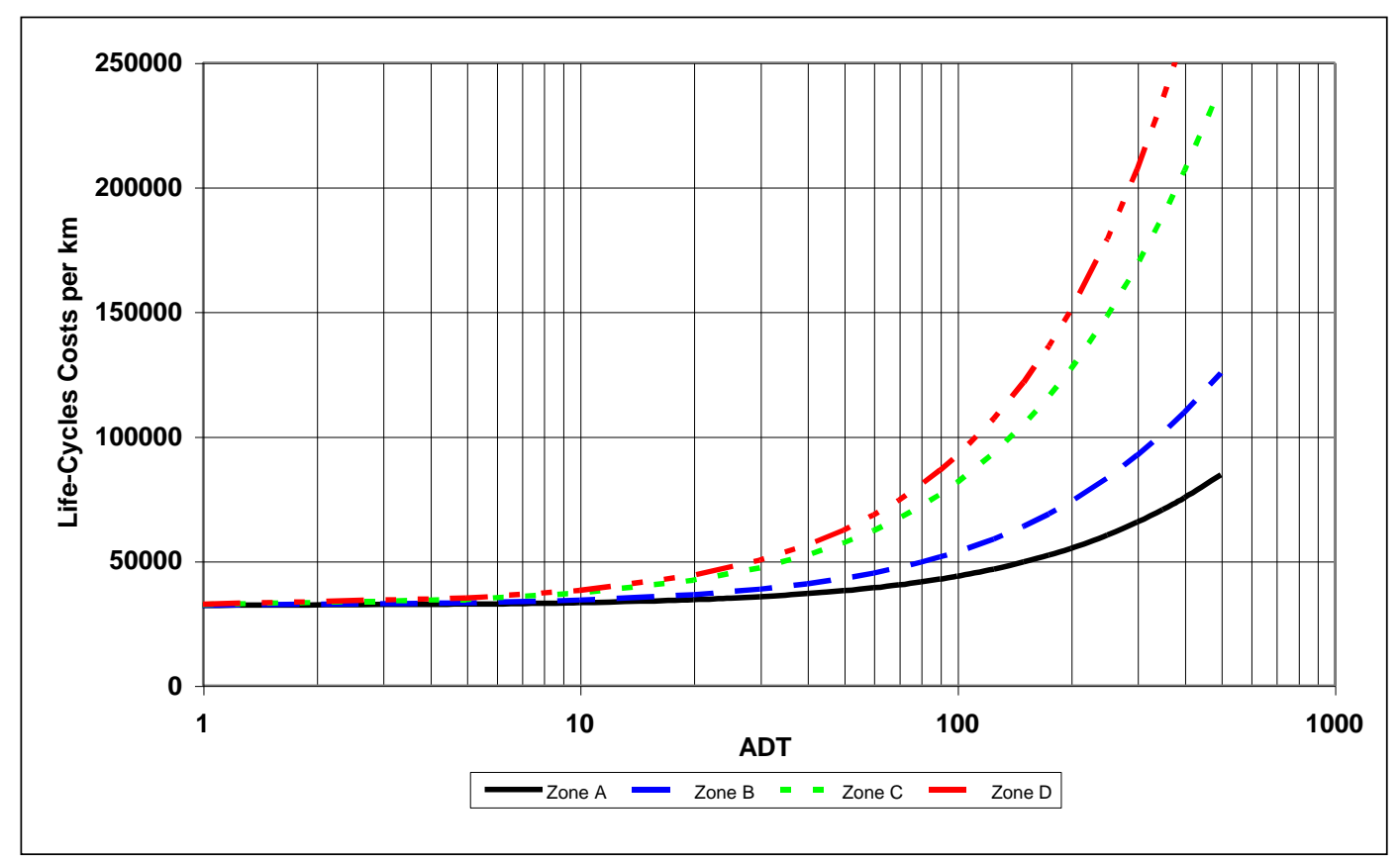

Figure 9. An illustration of the life-cycle costs associated with using different materials zones.

\section{Summary and Conclusions}

Data on the performance of gravel roads in six separate studies carried out in six countries (Ethiopia, Ghana, Lesotho, Mozambique, Uganda, and Zimbabwe) were collected and analyzed to develop a planning tool for the prediction of the performance of gravel wearing courses. One of the key features is that the tool is not 'data hungry' like many road performance prediction models. It is based on the use of two materials' properties, namely plasticity product and grading modulus within boundaries of traffic, rainfall, and gradient. It does not claim to present a more accurate gravel roads performance model such as those incorporating several variables (e.g., the Highway Development and Management Model 4 (HDM-4), Paterson [12]). The performance tool is corroborated by a recent publication in Australia of similar limits as shown in this study.

From the performance tool, an agency life-cycle costing tool for gravel roads was developed. Use of the tool enables maintenance units to easily estimate the agency life-cycle cost of maintaining gravel roads based on the materials available in the area. The study has shown that such a tool that relies on the use of few key variables, within a well-known boundary of other variables, can produce reasonable results for prediction of gravel wearing course performance. Whilst this approach might not be as rigorous as using HDM-4, it requires less data, is simple to use and is a useful tool in making a cost-effective case for sealing of unsealed roads based on factors such as those described above. 
Author Contributions: The study concept, methodology, and first draft of the article were developed by J.R.; data collection and analysis were undertaken by K.M., validation of the study, data, and analysis, and review and final editing were undertaken by A.O. All authors have read and agreed to the published version of the manuscript.

Funding: This research was funded by the International Labour Organisation (ILO) and the UKAid through the Research for Community Access Partnership (ReCAP).

Conflicts of Interest: The authors declare no conflict of interest.

\section{References}

1. Highway Research Board. The AASHO Road Test; National Academy of Sciences: Washington, DC, USA, 1962.

2. Federal Highway Authority and the South Dakota Local Technical Assistance Program. Gravel Roads Construction and Maintenance Guide; FHWA Technology Partnership Programs; FHWA: Washington, DC, USA, 2015.

3. Hodges, J.W.; Rolt, J.; Jones, T.E. The Kenya Road Transport Cost Study. (LR673); Transport and Road Research Laboratory: Crowthorne, UK, 1975.

4. Paige-Green, P. The Influence of Geotechnical Properties on the Performance of Gravel Wearing Course Materials. Ph.D. Thesis, University of Pretoria, Pretoria, RSA, 1989.

5. SweRoad; Department of State Roads Zimbabwe. Secondary and Feeder Road Development Programme. Final Report; Ministry of Transport and Energy: Harare, Zimbabwe, 1999.

6. Van Zyl, G.; Henderson, M.G.; Fourie, H.G. High Performance Gravel Roads: Gravel Road Specifications in South Africa and their Impact. 2003. Available online: railknowledgebank.com/Presto/content/GetDoc.axd (accessed on 27 January 2020).

7. Mukura, K. Performance Criteria and Life-Cycle Costing for Low-Volume and Labour-Based and Unpaved Roads in Ethiopia; UUPR/III/028/08, Report available on direct personal application only; Transport Research Laboratory: Crowthorne, UK, 2008.

8. Paige-Green, P.; Visser, A.T. Comparison of the Impact of Various Unpaved Road Performance Models on Management Decisions. Transp. Res. Rec. 1991, 2, 137-142.

9. Mukura, K. Increased Application of Labour-Based Methods through Appropriate Engineering Standards; INT/01/03/UKM; ILO: Geneva, Switzerland, 2005.

10. Cundhill, A.M. The MERLIN Road Roughness Machine: User Guide; TRL Report 229; TRL Limited: Crowthorne, UK, 1996.

11. Austroads. Sustainable Roads through Fit-for-Purpose Use of Available Materials: Technical Basis; Austroads Ltd.: Sydney, Australia, 2020.

12. Paterson, W.D.O. Road Deterioration and Maintenance Effects: Models for Planning and Management. In The Highway Design and Maintenance Standards Series; The World Bank: Washington, DC, USA, 1987.

(C) 2020 by the authors. Licensee MDPI, Basel, Switzerland. This article is an open access article distributed under the terms and conditions of the Creative Commons Attribution (CC BY) license (http://creativecommons.org/licenses/by/4.0/). 